Article

\title{
Evaluation of a Nanocomposite Based on Reduced Graphene Oxide and Gold Nanoparticles as an Electrochemical Platform for Detection of Sulfamethazine
}

\author{
Martin Silva ${ }^{(D)}$ and Ivana Cesarino *(D) \\ Sao Paulo State University (UNESP), School of Agriculture, Botucatu 18610-034, SP, Brazil; \\ martin.leme@unesp.br \\ * Correspondence: ivana.cesarino@unesp.br; Tel.: +55-14-3880-7404
}

Received: 6 May 2019; Accepted: 5 June 2019; Published: 8 June 2019

check for updates

\begin{abstract}
A nanocomposite based on reduced graphene oxide (rGO) and gold nanoparticles (AuNPs) was synthesized by the microwave-assisted hydrothermal method and applied in the determination of sulfamethazine (SMZ) in swine effluent using a glassy carbon (GC) electrode. The rGO-AuNPs nanocomposite was characterized morphologically, electrochemically and spectrochemically, showing that rGO was modified with the AuNPs. The GC/rGO-AuNPs electrode was optimized

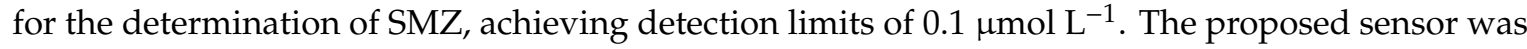
successfully applied to the determination of SMZ in synthetic swine effluent samples.
\end{abstract}

Keywords: graphene; gold nanoparticles; sulfamethazine; nanocomposite

\section{Introduction}

Sulfamethazine (SMZ), 4-amino- $N$-(4,6-dymethyl-2-pyrimide) benzenesulfonamide, is a frequently used sulfonamide with antibacterial properties to treat livestock disease such as gastrointestinal and respiratory tract infections in veterinary medicine [1]. This antibiotic is commonly used to promote growth [2] in swine production and its concentration in foodstuffs of animal origin is controlled by the European Commission (EC) which indicates a maximum level of $100 \mu \mathrm{g} \mathrm{kg}^{-1}$ for sulfonamide residue level [3-6].

SMZ is the most frequently used and often detected veterinary antibiotic. Determining SMZ levels in natural samples, as swine farming effluent, is an important issue due to major ecotoxicological problems such as groundwater and drinking water contamination $[7,8]$. In this way, the development of new analytical tools for determining low levels of SMZ is an extremely important. Several techniques have been developed for the determination of SMZ and sulfa drugs, such as, chromatography [8], polar organic integrative sampler technology [9], and immunoassays [10]. However, the continuous development of new electroanalytical sensors for determining environmental pollutants is a growing field; included in which is the electroanalytical assay based on a conducting polymer [11] and diamond electrodes [12].

Nanomaterials, in general, have been used in electroanalytical methods for modifying electrodes in order to determine SMZ in natural samples. Comparing the use of different materials for SMZ determination, the application of molecularly imprinted polymer technology by Prada et al. [6] found a limit of detection (LOD) of $0.3 \mu \mathrm{mol} \mathrm{L}^{-1}$. Rao et al. [12], using a diamond electrode with amperometric detection, found a high LOD of $0.05 \mu \mathrm{mol} \mathrm{L}{ }^{-1}$. Using carboxyl multiwalled carbon nanotubes to modify a glassy carbon electrode, the LOD of $0.032 \mu \mathrm{mol} \mathrm{L}^{-1}$ was determined by He et al. [13]. Fotouhi et al. [14] found a LOD of $6.1 \mu \mathrm{mol} \mathrm{L}^{-1}$ using a multiwalled nanotube film-coated glassy carbon electrode. 
Reduced graphene oxide (rGO) is an atomically thin sheet of carbon atoms [15]. It is a reduced form of graphene oxide, a material widely used as a support material for electrochemical applications due to its interesting electronic transport properties, high electrocatalytic activities, and large surface area-to-volume ratio [16]. Therefore, $\mathrm{rGO}$ has been applied synergistically with metal nanoparticles for detection of environmental pollutants in electrochemical sensors [17-20].

Gold nanoparticles (AuNPs) have biological compatibility, good conductivity, and they can enhance the sensitivity and stability of graphene-modified electrodes due to their unique surface, chemical inertness, high electron density, and strong optical absorption. Recently, gold nanoparticles have been applied in clinical chemistry [21], biosensors [22] genomics [23,24], vaccine making [25,26], immunoassay [27], diagnosis and microorganism control [28], the imaging of cancer-cells, drug delivery [29-31], and energy storage [32]. The combination of AuNPs with rGO has led to great opportunities and applications due to the synergistic effects of the component materials and this may enlarge the application area of graphene.

In this study, the rGO-AuNPs composite was synthesized, characterized, and applied for the first time in the determination of sulfamethazine in swine effluent. The proposed electrode is promising, allowing for the fast, simple, low cost, and sensitive determination of SMZ in environmental samples.

\section{Materials and Methods}

\subsection{Chemicals and Solutions}

All solutions were prepared with water purified from a Barnsted Nanopure system with resistivity $\geq 18 \mathrm{M} \Omega \mathrm{cm}$ (Thermo Scientific, USA). Graphite powder $(1-2 \mathrm{~mm})$ sulfamethazine standard and chloauric acid solution were purchased from Sigma Aldrich.

\subsection{Electroanalytical Procedures}

The electrochemical characterization of the electrodes was conducted by cyclic voltammetry (CV) and differential pulse voltammetry (DPV) at a PGSTAT30 Autolab electrochemical device (Eco Chemie, Utrecht, Netherlands). A three-electrode electrochemical system was assembled as follows: glassy carbon (GC) modified with graphene oxide (GO), rGO or rGO-AuNPs as working electrodes $(3.0 \mathrm{~mm}$ diameter), $\mathrm{Ag} / \mathrm{AgCl} / \mathrm{KCl}\left(3.0 \mathrm{~mol} \mathrm{~L}^{-1}\right)$ as the reference electrode and a Pt plate as the auxiliary electrode. All experiments were carried out at $25 \pm 1{ }^{\circ} \mathrm{C}$.

Electrochemical characterization of the working electrodes was performed using CV in $0.1 \mathrm{~mol}$ $\mathrm{L}^{-1} \mathrm{H}_{2} \mathrm{SO}_{4}$ and $5.0 \mathrm{mmol} \mathrm{L}^{-1}\left[\mathrm{Fe}(\mathrm{CN})_{6}\right]^{3-/ 4-}$ solutions with a scan rate of $50 \mathrm{mV} \mathrm{s}^{-1}$. DPV experiments were recorded in a $0.2 \mathrm{~mol} \mathrm{~L}^{-1} \mathrm{PBS}(\mathrm{pH} 8.0$ ) solution in the presence of $5.0 \mu \mathrm{mol} \mathrm{L}-1$ of SMZ standard. The experimental conditions of DPV were: scan rate of $10 \mathrm{mV} \mathrm{s}^{-1}$, pulse amplitude of $75 \mathrm{mV}$ and step potential of $2 \mathrm{mV}$.

The morphology of GO, rGO and rGO-AuNPs composites were characterized using field-emission gun-scanning electron microscopy (FEG-SEM) and the images were recorded using a model FEI Inspect F50 microscope (FEI Company, Hillsboro, OR, USA). The characterization of the GO functionalized was performed by Raman spectroscopy using Mira P Handheld (Metrohm, Herisau, Switzerland).

\subsection{Synthesis of $G O, r G O$ and $r G O-A u N P s$ Composite}

The graphene oxide (GO) was synthesized by an improved Hummer's method [18,33]. Briefly, $12.120 \mathrm{~g}$ of graphite was placed in a reaction flask in the presence of $11.952 \mathrm{~g}$ of $\mathrm{NaNO}_{3}$ and $400 \mathrm{~mL}$ of $\mathrm{H}_{2} \mathrm{SO}_{4}$. The reaction took place in an ice bath under vigorous stirring for $30 \mathrm{~min}$. Then, $60.093 \mathrm{~g}$ of $\mathrm{KMnO}_{4}$ was added to the suspension. Finally, $150 \mathrm{~mL}$ of $\mathrm{H}_{2} \mathrm{O}_{2}$ was added to the reaction. The obtained composite was centrifuged and cleaned several times with $\mathrm{HCl}(5 \%)$. The obtained GO composite was dried at $60^{\circ} \mathrm{C}$.

For the synthesis of rGO-AuNPs composite, the microwave-assisted hydrothermal (MAH) method was performed [34,35]. In a reaction flask, $80 \mathrm{~g}$ of GO (previously synthesized), $60 \mathrm{~mL}$ of ethylene 
glycol were sonicated for $15 \mathrm{~min}$. After this step, $1 \mathrm{~mL}$ of a $\mathrm{HAuCl}_{4}$ solution $\left(0.1 \mathrm{~mol} \mathrm{~L}^{-1}\right)$ was added within the solution and sonicated for $10 \mathrm{~min}$. Then, the $\mathrm{pH}$ was set at 9.0 using a diluted $\mathrm{NaOH}$ solution. The obtained suspension was placed in the MAH reactor under $140{ }^{\circ} \mathrm{C}$ for 16 min for synthesis. The obtained rGO-AuNPs composite was centrifuged at $3300 \mathrm{rpm}$ for $10 \mathrm{~min}$ and washed several times with ultrapure water. Finally, the composite was transferred to a Petri dish with $5 \mathrm{~mL}$ of pure grade ethanol and dried at $60^{\circ} \mathrm{C}$.

The synthesis of rGO was also performed as described above, but without the addition of $\mathrm{HAuCl}_{4}$.

\subsection{Preparation of the Electrodes}

Briefly, all GC working electrode surfaces were polished with $0.3 \mu \mathrm{m}$ alumina slurries, then a double sonication step was employed; firstly, they were sonicated for $5 \mathrm{~min}$ in ethanol and $5 \mathrm{~min}$ in water, and then dried at room temperature. A suspension of $0.0500 \mathrm{mg} \mathrm{mL}^{-1}$ was prepared using an ultrasonic probe for $30 \mathrm{~min}$. Then, $10 \mu \mathrm{L}$ of the suspension was dropped on the surface of the cleaned and polished GC electrode and dried at room temperature. The electrodes modified with GO and rGO nanocomposites were prepared with the same protocol for comparison purposes.

\subsection{Preparation of Swine Effluent Samples for SMZ Analysis}

The proposed GC/rGO-AuNPs sensor was evaluated in the detection of SMZ in synthetic swine effluent using the standard addition method. The effluent was prepared by a solution containing 483 $\left(\mathrm{NH}_{4}{ }^{+}\right), 0.93\left(\mathrm{NO}_{3}{ }^{-}\right), 98\left(\mathrm{PO}_{4}^{-}\right), 485\left(\mathrm{~K}^{+}\right), 122\left(\mathrm{Ca}^{2+}\right), 40\left(\mathrm{Mg}^{2+}\right) 301\left(\mathrm{Cl}^{-}\right), 7.87\left(\mathrm{Fe}^{2+}\right), 34(\mathrm{~S}), 175\left(\mathrm{Na}^{+}\right)$ $0.68(\mathrm{~B}), 0.88\left(\mathrm{Mn}^{2+}\right), 3.07\left(\mathrm{Zn}^{2+}\right), 1.21\left(\mathrm{Cu}^{2+}\right), 0.02\left(\mathrm{Mo}^{2+}\right)$ and $0.02\left(\mathrm{Co}^{2+}\right) \mathrm{mg} \mathrm{L}^{-1}$ of each component. Known amounts of the standard SMZ solution were added to a $5.0 \mathrm{~mL}$ aliquot of the synthetic swine effluent mixed with $15.0 \mathrm{~mL}$ of $0.2 \mathrm{~mol} \mathrm{~L}^{-1} \mathrm{PBS} \mathrm{pH}$ 8.0, giving a final concentration of $1.0 \mu \mathrm{mol} \mathrm{L}^{-1}$ SMZ. No additional sample treatment was done. The SMZ content was determined by three successive additions of aliquots of the standard SMZ solution.

\section{Results and Discussion}

\subsection{Characterization of the $\mathrm{GO}-A$ uNPs Composite}

The surface morphology of the rGO and rGO-AuNPs composites was characterized by FEG-SEM, as shown in Figure 1. Figure $1 \mathrm{~A}$ presents the images of $\mathrm{rGO}$, in which the graphitic material displayed a typical wrinkled structure with plenty of corrugations. On the other hand, Figure 1B displays the obtained micrograph for the rGO-AuNPs nanocomposite, showing the incorporation of AuNPs on rGO surface. In addition, the AuNPs on the composite showed sizes ranging from 5 to $30 \mathrm{~nm}$. The average size of nanoparticles was obtained by ImageJ free software.

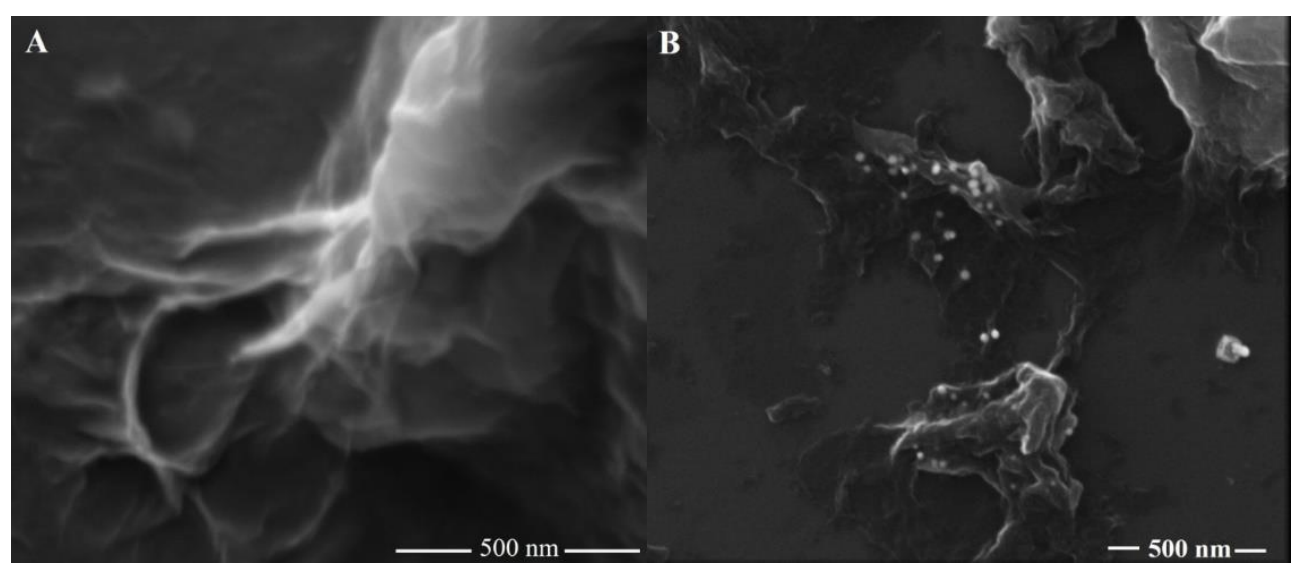

Figure 1. FEG-SEM micrographs for: (A) rGO and (B) rGO-AuNPs composite. 
The modified rGO with AuNPs was also characterized electrochemically. As a result, CV experiments were conducted in a $0.1 \mathrm{~mol} \mathrm{~L}^{-1}$ of $\mathrm{H}_{2} \mathrm{SO}_{4}$ solution, using a scan rate of $50 \mathrm{mV} \mathrm{s}^{-1}$ in the potential range from 0.0 to $+1.6 \mathrm{~V}$. In order to compare the modification, the electrochemical behavior of the rGO-AuNPs proposed composite was compared with the voltammetric response of the GC/rGO electrode. The cyclic voltammograms in Figure 2, shows no electrochemical process for the voltammetric response of the GC/rGO electrode. On the other hand, the GC electrode modified with the rGO-AuNPs composite presented peaks at +1.29 and $+0.88 \mathrm{~V}$, corresponding to the Au nanoparticles oxidation and Au oxide reduction, respectively [7]. Hence, the CV experiment, as well as the MEV micrographs, successfully characterized the presence of AuNPs on the nanocomposite.

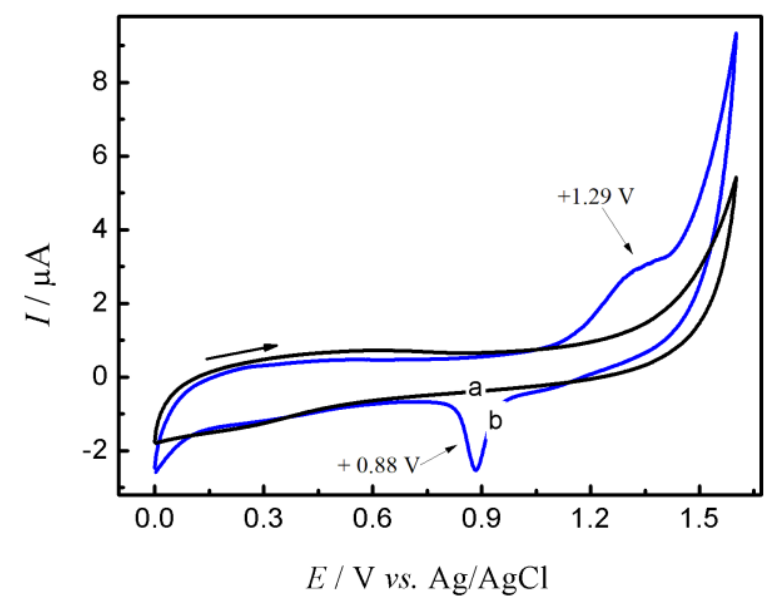

Figure 2. Cyclic voltammetry characterization in $0.1 \mathrm{~mol} \mathrm{~L}^{-1}$ of $\mathrm{H}_{2} \mathrm{SO}_{4}$ with a scan rate of $50 \mathrm{mV} \mathrm{s}^{-1}$ for the electrodes: (a) GC/rGO and (b) GC/rGO-AuNPs.

The reduced form of GO offers a great improvement in several electrochemical properties, such as electronic mobility, higher surface area, and high electrocatalytic activity. Therefore, CV experiments were carried out in order to evaluate the response of the nanomaterials in the presence of $5.0 \mathrm{mmol}$ $\mathrm{L}^{-1}$ of the couple redox $[\mathrm{Fe}(\mathrm{CN}) 6]^{3-/ 4-}$ at $50 \mathrm{mV} \mathrm{s}^{-1}$ scan rate. The results are presented in Figure 3 . The voltammetric profiles presented well-defined oxidation and reduction peaks for the three electrodes studied. For both, GC/rGO (b) and GC/rGO-AuNPs (c) electrodes, the potentials were approximately $+0.44 \mathrm{~V}$ and $+0.33 \mathrm{~V}$ vs. $\mathrm{Ag} / \mathrm{AgCl} / \mathrm{KCl}\left(3.0 \mathrm{~mol} \mathrm{~L}^{-1}\right)$. However, for the GC/GO (a) electrode the peaks were at $+0.51 \mathrm{~V}$ and $+0.20 \mathrm{~V}$ for oxidation and reduction process, respectively. The GC/rGO electrode (curve b) showed a 1.4-fold increase in the peak current when compared to the GC/GO electrode (curve a), an increase due to the presence of defects introduced by functional groups or vacancies in the reduced graphene oxide, causing the electrons to be transferred to the electrolytic medium more easily.

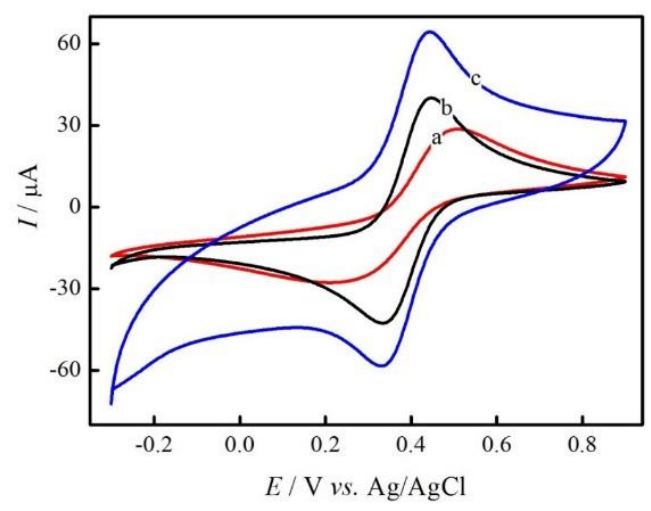

Figure 3. CV scans of the electrodes: (a) GC/GO, (b) GC/rGO and (c) GC/rGO-AuNPs in $0.1 \mathrm{~mol} \mathrm{~L}^{-1}$ $\mathrm{H}_{2} \mathrm{SO}_{4}$ containing $5.0 \mathrm{mmol} \mathrm{L}-1$ of the redox couple $[\mathrm{Fe}(\mathrm{CN} 6)]^{3-/ 4-}$ with a scan rate of $50 \mathrm{mV} \mathrm{s}^{-1}$. 
The GC electrode modified with the rGO-AuNPs composite (curve c) showed a 2.2-fold increase in the peak current when compared to the GC/GO electrode (curve a) and a 1.6-fold increase in the peak relative to the $\mathrm{GC} / \mathrm{rGO}$ electrode (curve $\mathrm{b}$ ). This increase can be attributed to the possible mediation effect caused by the AuNPs/reduced graphene oxide system.

Further, the rGO-AuNPs composite was characterized by UV-Vis spectrophotometry. Figure 4 displays the UV-vis spectra of (a) GO, (b) rGO and (c) rGO-AuNPs. UV-vis spectrum of GO showed two maximum bands at 225 and $300 \mathrm{~nm}$, which are due to the $\pi \rightarrow \pi^{*}$ transition of aromatic C-C bonds and $\mathrm{n} \rightarrow \pi^{*}$ transition of $\mathrm{C}=\mathrm{O}$. However, rGO showed only one maximum band at $240 \mathrm{~nm}$. These results were expected since $\mathrm{rGO}$ has a lower $\mathrm{C} / \mathrm{O}$ coefficient due to the removal of oxygen functionalities and establishment of $\mathrm{C}=\mathrm{C}$ conjugated graphene structures. The rGO-AuNPs composite exhibited a maximum band at $235 \mathrm{~nm}$ and small band at $570 \mathrm{~nm}$. Gold nanoparticles have been reported to shows absorption bands in the range from $450-600 \mathrm{~nm}$, the small band for AuNPs is due to the dilution effect of rGO-AuNPs during experimental procedures. The absorption at $570 \mathrm{~nm}$ is due to the plasmon resonance of AuNPs. Previous works in literature described the Fourier transform infrared (FTIR) experiments as a methodology for differentiation between GO, rGO and rGO-AuNPs. Ali et al. [35,36] investigated the modification of multi-walled carbon nanotubes (MWCNTs) with 2,2,6,6-tetramethylpiperidine-1-oxyl (TEMPO) for a symmetric supercapacitor. The Fourier-transform infrared spectroscopy (FTIR) experiments elucidated the functional groups on the modified MWCNTs and successfully characterized the composite.

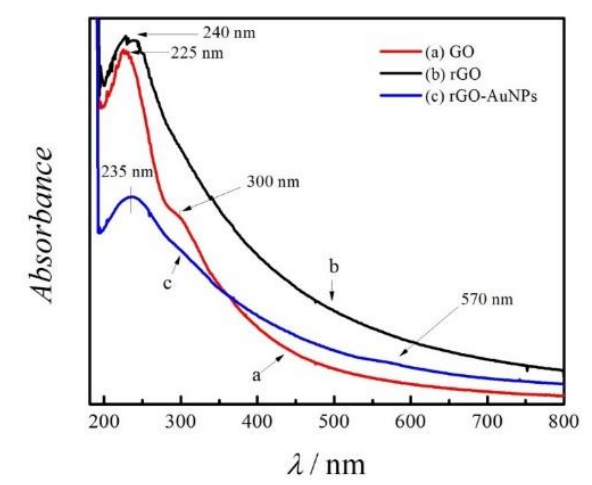

Figure 4. UV-vis spectra for the following nanomaterials (a) GO, (b) rGO and (c) rGO-AuNPs.

For the characterization of the GO reduction to rGO, these nanomaterials were analyzed by Raman spectroscopy as presented in Figure 5. It was observed that the synthesized GO and rGO presented two characteristic absorption bands in its Raman spectrum: the $G$ band at around $1585 \mathrm{~cm}^{-1}$ and the D band at $1355 \mathrm{~cm}^{-1}$. The $\mathrm{G}$ band corresponds to the bond stretching of $\mathrm{sp}^{2}$ carbon pairs. The $\mathrm{D}$ band is associated with the breathing mode of aromatic rings with dangling bond in-plane terminations [18]. The relationship between the intensity of the $\mathrm{D}$ band $\left(I_{\mathrm{D}}\right)$ and $\mathrm{G}$ band $\left(I_{\mathrm{G}}\right)$ is usually employed to evaluate the size of the in-plane $\mathrm{sp}^{2}$ domains for carbon materials. The obtained values for the $I_{\mathrm{D}} / I_{G}$ ratio was 0.94 and 1.05 for GO and rGO, respectively. The higher magnitude of the D band for the rGO suggests an increase in disorder, and indicates that during the reduction of GO, most of the oxygenated functional groups were removed, resulting in a decrease in the average size of the $\mathrm{sp}^{2}$ domains [37]. 


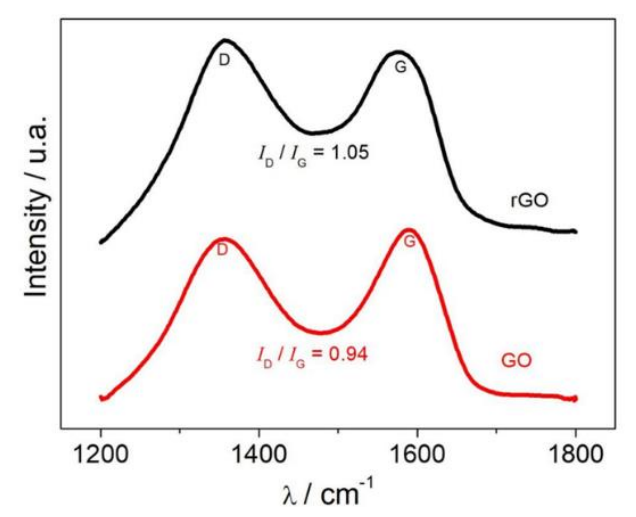

Figure 5. Spectroscopic Raman characterizations for the nanomaterials.

\subsection{Electrochemical Behavior of GC/rGO-AuNPs Composite Electrode on the Sulfamethazine Oxidation Process}

The electrochemical behavior of SMZ on the GC/rGO-AuNPs composite electrode was carried out in $0.2 \mathrm{~mol} \mathrm{L-1} \mathrm{PBS} \mathrm{pH} \mathrm{8.0,} \mathrm{containing} 50.0 \mu \mathrm{mol} \mathrm{L}^{-1}$ of SMZ, by cyclic voltammetry experiments, with a scan rate of $50 \mathrm{~m} \mathrm{~V} \mathrm{~s}^{-1}$. Figure 6 shows no electrochemical process in the absence of SMZ standard (curve a). However, when the SMZ is added into the solution (curve b), a well-defined irreversible oxidation peak at $+0.89 \mathrm{~V}$ vs. $\mathrm{Ag} / \mathrm{AgCl} / \mathrm{KCl}\left(3.0 \mathrm{~mol} \mathrm{~L}^{-1}\right)$ is observed, demonstrating that it is possible to perform the determination of SMZ directly.

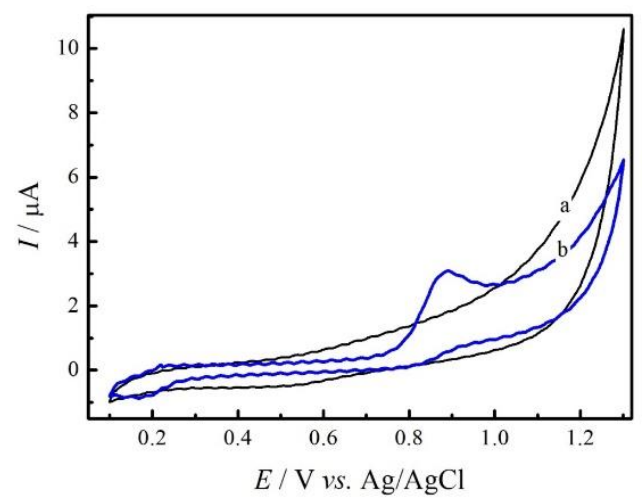

Figure 6. Electrochemical characterization of SMZ in $0.2 \mathrm{~mol} \mathrm{~L}^{-1} \mathrm{PBS} \mathrm{pH} 8.0$ in the absence (a) and in the presence (b) of $50.0 \mu \mathrm{mol} \mathrm{L}-1$ of SMZ with a scanning rate of $50 \mathrm{mV} \mathrm{s}^{-1}$.

To compare the electrochemical performance of the proposed electrode in determining SMZ, DPV experiments were performed in the potential range $+0.2 \mathrm{~V}$ to $+1.2 \mathrm{~V} \mathrm{vs.} \mathrm{Ag} / \mathrm{AgCl} / \mathrm{KCl}\left(3.0 \mathrm{~mol} \mathrm{~L}^{-1}\right)$ in a $0.2 \mathrm{~mol} \mathrm{~L}^{-1} \mathrm{PBS}$ (pH 8.0) containing $5.0 \mu \mathrm{mol} \mathrm{L}{ }^{-1}$ of SMZ, using the following electrodes: GC (a curve), GC/GO (curve b), GC/rGO (curve c) and GC/rGO-AuNPs (curve d), as shown in Figure 7. By observing the voltammetric profiles, it can be noticed that the maximum anodic peak currents, for all the electrodes studied, presented potentials relatively close to $+0.80 \mathrm{~V}$ vs. $\mathrm{Ag} / \mathrm{AgCl} \mathrm{KCl}\left(3.0 \mathrm{~mol} \mathrm{~L}^{-1}\right)$, under the conditions previously described. However, the GC/rGO-AuNPs electrode profile (curve d) exhibited the highest anodic current intensity for SMZ in comparison to the others. The increase in peak current intensity for $\mathrm{SMZ}$ oxidation at this electrode showed an increase of $60 \%$ when compared to the electrode containing only rGO (curve c). The GC/GO electrode (curve b) showed a 2.2-fold increase in the intensity of the peak current for the SMZ oxidation and, compared to the GC electrode (curve a), this factor practically quadrupled. The relative increase in the current values reflects the increase of the electroactive surface area, that is, a higher interaction of the analyte occurs with the active sites of the composite rGO-AuNPs synthesized compared to the others, possibly caused by the insertion of the gold in the reduced graphene sheets. Thus, the synergistic combination between 
reduced graphene oxide and gold nanoparticles becomes evident, leading to an increase in the peak current for the oxidation of SMZ.

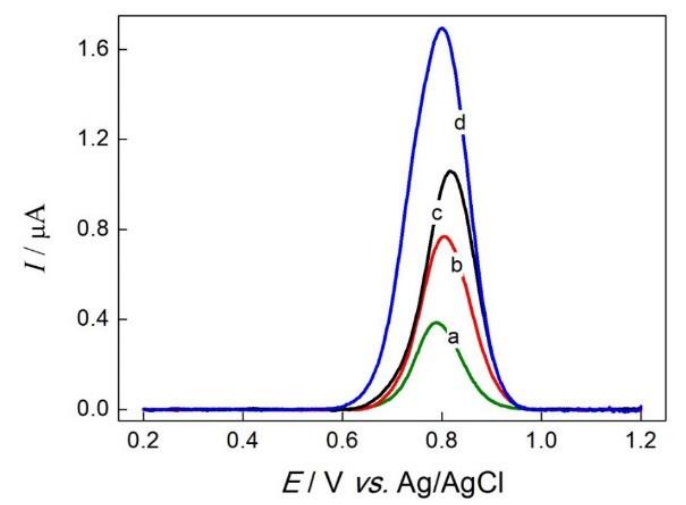

Figure 7. DPV voltammograms obtained in $0.2 \mathrm{~mol} \mathrm{~L}^{-1} \mathrm{PBS} \mathrm{pH} 8.0$ containing $5.0 \mu \mathrm{mol} \mathrm{L}-1$ of SMZ for the following electrodes: (a) bare GC, (b) GC/GO, (c) GC/rGO and (d) GC/rGO-AuNPs.

\subsection{Effect of $\mathrm{pH}$ and Support Electrolyte on SMZ Oxidation}

The effect of the support electrolyte on SMZ oxidation was investigated using DPV experiments. Figure 8A displays the effect of tris(hydroxymethyl) aminomethane (curve a), acetate (curve b), Britton-Robinson (curve c) and PBS (curve d) solutions at $\mathrm{pH} 8.0$ in the presence of $5.0 \mu \mathrm{mol} \mathrm{L}-1$ of SMZ. The PBS showed the higher anodic peak response for the analyte. Therefore, the $\mathrm{pH}$ evaluation and subsequent analysis were conducted using this solution.
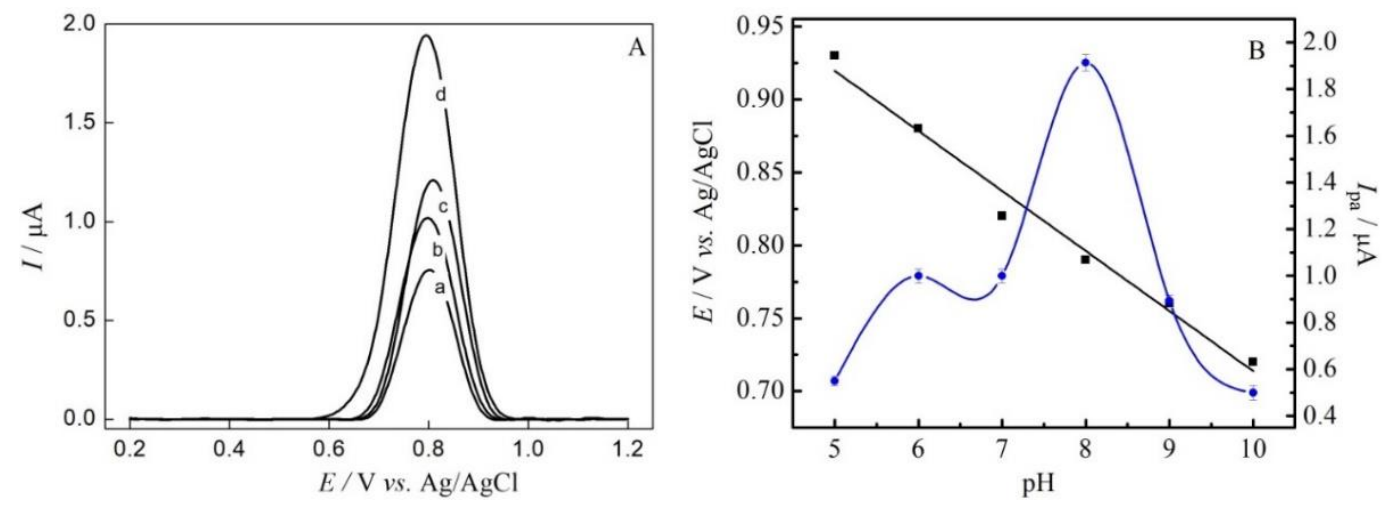

Figure 8. (A) Comparison of the DPV experiments for $5.0 \mu \mathrm{mol} \mathrm{L}{ }^{-1}$ of SMZ in different support electrolytes, keeping the $\mathrm{pH} 8.0$ and the ionic strength of $0.2 \mathrm{~mol} \mathrm{~L}^{-1}$ for: (a) Tris(hydroxymethyl) aminomethane, (b) Britton-Robinson, (c) Acetate and (d) PBS. (B) Effect of pH on the peak potential (ם) and peak current $(\bullet)$ for SMZ oxidation on the GC/rGO-AuNPs composite electrode using $0.2 \mathrm{~mol} \mathrm{~L}^{-1}$ PBS containing $5.0 \mu \mathrm{mol} \mathrm{L}-1$ of SMZ.

To analyze the mechanism of SMZ oxidation on the GC/rGO-AuNPs composite electrode, the dependence on the electrochemical oxidation of $\mathrm{SMZ}$ on $\mathrm{pH}$ was studied by DPV experiments at $\mathrm{pHs}$ ranging from 5.0 to 10.0 in PBS containing $5.0 \mu \mathrm{mol} \mathrm{L}^{-1}$ of SMZ (Figure 8B). Previous work combining electrochemical studies and molecular modelling techniques confirmed a better understanding of the oxidation process which indicates that $\mathrm{SMZ}(0)$ is the species that effectively participates in the oxidation process [7]. The Epa vs. $\mathrm{pH}$ showed a linear relationship, with a slope of $51 \mathrm{mV}$ per $\mathrm{pH}$ unit, which indicates the same number of protons and electrons during the electrooxidation of SMZ. The plot of Ipa vs. pH for SMZ shows that the anodic peak current increases in the $\mathrm{pH}$ range of 5.0 to 8.0, reaching a maximum value at $\mathrm{pH} 8.0$. Above $\mathrm{pH} 8.0$ an abrupt decrease in the Ipa is observed. 
This value was expected because the $\mathrm{p} k_{\mathrm{a}}$ of the SMZ is 7.4 [36]. Therefore, $\mathrm{pH} 8.0$ was chosen for use in following experiments.

\subsection{Optimization of $G C / r G O-A u N P s$ Electrode Preparation}

The effect of the amount of the chloroauric acid $\left(\mathrm{HAuCl}_{4}\right)$ in the synthesis of rGO-AuNPs were investigated using DPV. Figure 9A shows that $500 \mu \mathrm{L}\left(25 \% \mathrm{w} / \mathrm{w}\right.$ in relation to GO) of a $0.1 \mathrm{~mol} \mathrm{~L}^{-1}$ solution of $\mathrm{HAuCl}_{4}$ had the best response for the oxidation of $5.0 \mu \mathrm{mol} \mathrm{L}-1$ of SMZ. Furthermore, the amount of rGO-AuNPs composite on the electrode preparation was evaluated in the range from 0.0125 to $0.1000 \mathrm{mg} \mathrm{mL}^{-1}$. As displayed on Figure $9 \mathrm{~B}$, the amount of $0.0500 \mathrm{mg} \mathrm{mL}^{-1}$ was chosen for the subsequent analysis. Since higher concentrations of the composite can interfere negatively on the electron-transfer process through electrode/electrolyte interface, hence the amount of $0.0500 \mathrm{mg} \mathrm{mL}^{-1}$ was used for further experiments.
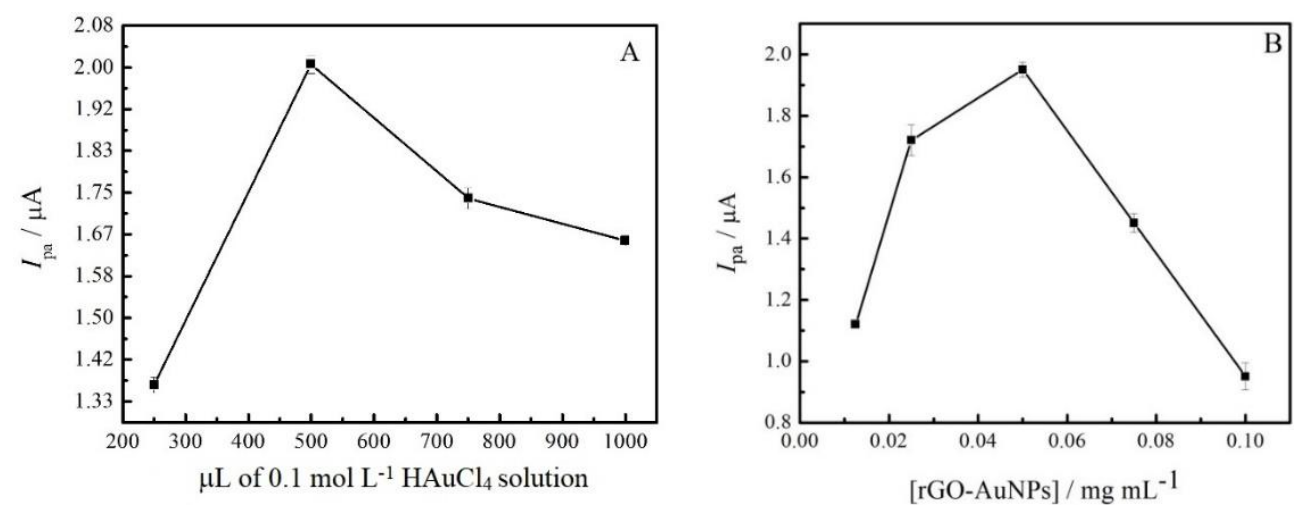

Figure 9. Optimization of the electrode composition using DPV in $0.2 \mathrm{~mol} \mathrm{~L}^{-1} \mathrm{PBS} \mathrm{pH} 8.0$ containing $5.0 \mu \mathrm{mol} \mathrm{L}{ }^{-1}$ of SMZ: (A) influence of the chloroauric acid amount in the electrode preparation and (B) influence of the amount of the rGO-AuNPs composite in the electrode preparation.

\subsection{Calibration Curve}

The analytical curve for the determination of SMZ, under optimized conditions, was recorded by DPV experiments (triplicate) using the GC/rGO-AuNPs electrode. The results are shown in Figure 10. The experiments revealed a good linear response to SMZ concentrations ranging from 0.5 to $6.5 \mu \mathrm{mol}$ $\mathrm{L}^{-1}$. The respective equation is presented as follows:

$$
I_{\mathrm{pa}}(\mu \mathrm{A})=9.33 \times 10^{-9}(\mu \mathrm{A})+0.32\left(\mu \mathrm{A} / \mu \mathrm{mol} \mathrm{L}^{-1}\right)[\mathrm{SMZ}]\left(\mu \mathrm{mol} \mathrm{L}^{-1}\right)
$$

with a correlation coefficient of $0.997(n=7)$. The limit of detection (LOD) obtained was $0.1 \mu \mathrm{mol} \mathrm{L} \mathrm{L}^{-1}$, which was determined using a $3 \sigma /$ slope ratio, where $\sigma$ is the standard deviation of the mean value for 10 voltammograms of the blank. 


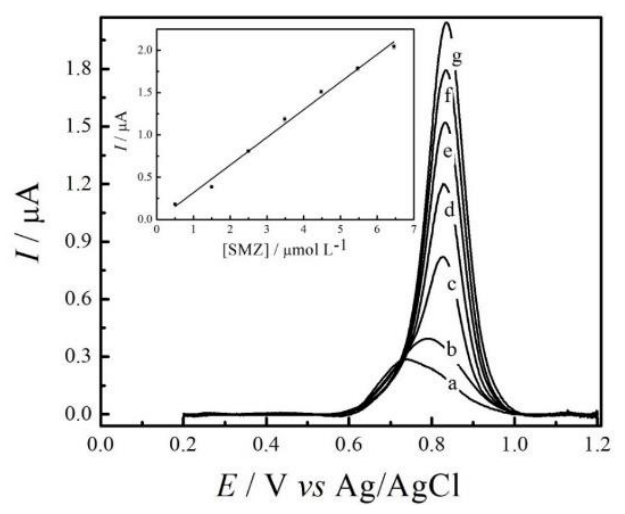

Figure 10. DPV voltammograms for GC/rGO-AuNPs composite electrode, with the optimized parameters. The SMZ concentrations in $\mu \mathrm{mol} \mathrm{L} \mathrm{L}^{-1}$ are: (a) 0.5, (b) 1.5, (c) 2.5, (d) 3.5, (e) 4.5, (f) 5.5, and (g) 6.5. Inset: linear dependence of the peaks current with SMZ concentrations.

When comparing the results for the GC/rGO-AuNPs electrode with other electrochemical methods, we found that the molecularly imprinted polymer technology [6], a diamond electrode with amperometric detection [12] and multiwalled nanotube-film coated GC electrode [14] showed higher detection limits of $3.0 \times 10^{-7} \mathrm{~mol} \mathrm{~L}^{-1}, 50 \mathrm{nmol} \mathrm{L}^{-1}$ and $6.1 \mu \mathrm{mol} \mathrm{L}^{-1}$, respectively. The lower detection of $3.19 \times 10^{-8} \mathrm{~mol} \mathrm{~L}^{-1}$ was determined using a carboxyl multiwalled carbon nanotube-modified GC electrode. The advantages of the GC/rGO-AuNPs electrode are its reproducibility and repeatability in the experiments, and its easy preparation and low cost, since the amount of material that is used for the preparation of the sensor is very small $\left(0.0500 \mathrm{mg} \mathrm{mL}^{-1}\right)$. In addition, all voltammograms presented in this work are raw data, direct from the GPES software without any treatment.

The reproducibility experiments for the GC/rGO-AuNPs electrode were conducted in five experiments, consisting of ten sequential DPV voltammograms. In order to evaluate the best conditions for these experiments, each electrode was evaluated on different days by preparing different working electrode films. The DPV voltammograms were performed in a $0.2 \mathrm{~mol} \mathrm{~L}^{-1} \mathrm{PBS} \mathrm{pH}$ 8.0, containing $5.0 \mu \mathrm{mol} \mathrm{L}{ }^{-1}$ of SMZ. The standard deviation obtained was $1.0 \%$; furthermore, the repeatability of $0.6 \%$ was evaluated by the standard deviation of ten DPV voltammograms using the same solution for all experiments.

\subsection{Influence of Interferences in the Determination of SMZ}

The possibility of determining SMZ in the presence of other organic wastewater compounds, including endocrine disruptors, pesticides and another antibiotic was investigated. The endocrine disruptor studied was estriol, the pesticide was carbaryl and the antibiotic was trimethoprim. In DPV experiments, oxidation processes of the interfering estriol and trimethoprim in the studied range of +0.2 and $+1.2 \mathrm{~V}$ vs. $\mathrm{Ag} / \mathrm{AgCl} / \mathrm{KCl}\left(3.0 \mathrm{~mol} \mathrm{~L}^{-1}\right)$ was observed at the potential about of $+0.45 \mathrm{~V}$ and + $1.1 \mathrm{~V}$, respectively. The separation of the peaks suggests that a simultaneous analysis of the molecules and SMZ can be performed. The effect of estriol, carbaryl and trimethoprim in the SMZ oxidation peak currents were evaluated using a $0.2-\mathrm{mol} \mathrm{L}^{-1} \mathrm{PBS} \mathrm{pH} 8.0$ containing a fixed concentration of $2.0 \mu \mathrm{mol} \mathrm{L}-1$ of SMZ, and sequential additions of 1.0, 2.0 and $4.0 \mu \mathrm{mol} \mathrm{L}^{-1}$ of estriol, carbaryl and trimethoprim. Recoveries of $97 \%, 95 \%$, and $104 \%$ of SMZ were obtained when 1.0, 2.0, and $4.0 \mu \mathrm{mol}$ $\mathrm{L}^{-1}$ of estriol were added to each measurement. Already for the carbaryl interferer, recoveries of 93, 91, and 109\% were obtained for SMZ, in the respective additions of 1.0, 2.0, and $4.0 \mu \mathrm{mol} \mathrm{L} \mathrm{L}^{-1}$ of carbaryl. On the other hand, recoveries of $98 \%, 95 \%$, and $101 \%$ of SMZ were obtained when 1.0, 2.0, and $4.0 \mu \mathrm{mol} \mathrm{L}-1$ of trimethoprim were added to the solution. It is possible to observe that the carbaryl pesticide presented the greatest interference, probably to be oxidized at a very similar potential of SMZ. The other interferents studied did not significantly interfere in the SMZ oxidation process. 


\subsection{Determination of SMZ in Synthetic Swine Effluent}

The GC/rGO-AuNPs electrode was applied in the quantification of SMZ in synthetic wastewater simulating the swine effluent, prepared as described in Section 2.5. The results (mean \pm SD) for triplicate determinations were $1.06 \pm 0.02 \mu \mathrm{mol} \mathrm{L}^{-1}$ for SMZ. The relative errors for each measurement were $\mathrm{E} 1=5.9 \%, \mathrm{E} 2=5.1 \%$ and $\mathrm{E} 3=8.0 \%$. SMZ recoveries obtained were $105.4 \%, 106.3 \%$ and $111.1 \%$ from synthetic swine effluent $(\mathrm{n}=3)$ for samples spiked with 1.0, 2.0 and $3.0 \mu \mathrm{mol} \mathrm{L}{ }^{-1}$ of SMZ.

There were no significant differences between the found and added concentrations of SMZ, indicating that the GC/rGO-AuNPs could be successfully used for the determination of SMZ in swine effluent under the optimized conditions and using the standard addition approach.

\section{Conclusions}

A composite based on reduced graphene oxide and gold nanoparticles was used in the modification of a glassy carbon electrode and evaluated for the determination of sulfamethazine antibiotic in swine effluent. The proposed composite was synthesized by the microwave-assisted hydrothermal method and successfully characterized morphologically, electrochemically, and spectrochemically, showing that GO was functionalized to rGO and the rGO was modified with the AuNPs.

The rGO-AuNPs composite improved the sensitivity of the GC, GC/GO and GC/rGO electrodes, and demonstrated easy preparation and low cost, which augurs well for future applications in this area.

Author Contributions: Funding acquisition, I.C.; Investigation, M.S. and I.C.; Methodology, M.S. and I.C.; Project administration, I.C.; Supervision, I.C.; Writing-original draft, M.S.; Writing-review \& editing, I.C.

Funding: The authors thank the Fundação de Amparo à Pesquisa do Estado de São Paulo-FAPESP (2017/24274-3) for the financial support given for this research.

Conflicts of Interest: The authors declare no conflict of interest.

\section{References}

1. De Zayas-Blanco, F.; García-Falcón, M.; Simal-Gándara, J. Determination of sulfamethazine in milk by solid phase extraction and liquid chromatographic separation with ultraviolet detection. Food Control 2004, 15, 375-378. [CrossRef]

2. Dixon-Holland, D.E.; Katz, S.E. Competitive direct enzyme-linked immunosorbent screening assay for the detection of sulfamethazine contamination of animal feeds. J. Assoc. Off. Anal. Chem. 1991, 74, 784-789. [PubMed]

3. Laurensen, J.J.; Nouws, J.F.M. Monitoring of chloramphenicol residues in muscle tissues by an immunoassay (La Carte ${ }^{\circledR}$ test). Vet. Q. 1990, 12, 121-123. [CrossRef] [PubMed]

4. Church, T.L.; Janzen, E.D.; Sisodia, C.S.; Radostits, O.M. Blood levels of sulfamethazine achieved in beef calves on medicated drinking water. Can. Vet. J. 1979, 20, 41-44. [PubMed]

5. Joint FAO/WHO Expert Committee on Food Additives. International Program on Chemical Safety. In Toxicological Evaluation of Certain food Additives and Contaminants; World Health Organization: Geneva, Switzerland, 1993; ISBN 9241660325.

6. Guzmán-Vázquez De Prada, A.; Martínez-Ruiz, P.; Reviejo, A.J.; Pingarrón, J.M. Solid-phase molecularly imprinted on-line preconcentration and voltammetric determination of sulfamethazine in milk. Anal. Chim. Acta 2005, 539, 125-132. [CrossRef]

7. Cesarino, I.; Simões, R.P.; Lavarda, F.C.; Batagin-Neto, A. Electrochemical oxidation of sulfamethazine on a glassy carbon electrode modified with graphene and gold nanoparticles. Electrochim. Acta 2016, 192, 8-14. [CrossRef]

8. Yang, Y.; Shi, J.; Yang, Y.; Yin, J.; Zhang, J.; Shao, B. Transformation of sulfamethazine during the chlorination disinfection process: Transformation, kinetics, and toxicology assessment. J. Environ. Sci. 2018, 76, 48-56. [CrossRef]

9. Washington, M.T.; Moorman, T.B.; Soupir, M.L.; Shelley, M.; Morrow, A.J. Monitoring tylosin and sulfamethazine in a tile-drained agricultural watershed using polar organic chemical integrative sampler (POCIS). Sci. Total Environ. 2018, 612, 358-367. [CrossRef] 
10. Peng, D.; Li, Z.; Wang, Y.; Liu, Z.; Sheng, F.; Yuan, Z. Enzyme-linked immunoassay based on imprinted microspheres for the detection of sulfamethazine residue. J. Chromatogr. A 2017, 1506, 9-17. [CrossRef]

11. Su, Y.-L.; Cheng, S.-H. A novel electroanalytical assay for sulfamethazine determination in food samples based on conducting polymer nanocomposite-modified electrodes. Talanta 2018, 180, 81-89. [CrossRef]

12. Rao, T.N.; Sarada, B.V.; Tryk, D.A.; Fujishima, A. Electroanalytical study of sulfa drugs at diamond electrodes and their determination by HPLC with amperometric detection. J. Electroanal. Chem. 2000, 491, 175-181. [CrossRef]

13. He, B.; Chen, W.; Using, E.; Multiwalled, C.; Nanotubes, C.; He, B.; Chen, W.; Using, E.; Multiwalled, C.; Nanotubes, C. Voltammetric Determination of Sulfonamides with a Modified Glassy Carbon Electrode Using Carboxyl Multiwalled Carbon Nanotubes. J. Braz. Chem. Soc. 2016, 27, 2216-2225. [CrossRef]

14. Fotouhi, L.; Zabeti, M. Electrochemical Oxidation of Sulfamethazine on Multi-Walled Nanotube Film Coated Glassy Carbon Electrode. Univ. Kashan 2014, 4, 161-166.

15. Becerril, H.A.; Mao, J.; Liu, Z.; Stoltenberg, R.M.; Bao, Z.; Chen, Y. Evaluation of Solution-Processed Reduced Graphene Oxide Films as Transparent Conductors. ACS Nano 2008, 2, 463-470. [CrossRef] [PubMed]

16. Gao, C.; Huang, X.J. Voltammetric determination of mercury(II). TrAC Trends Anal. Chem. 2013, 51, 1-12. [CrossRef]

17. Cesarino, I.; Hümmelgen, I.A. An additional tool towards overcoming absence of specificity of carbon nanostructure-based electrochemical sensors-Application to estriol and estradiol detection and distinction. J. Solid State Electrochem. 2015, 19, 3045-3050. [CrossRef]

18. Cesarino, I.; Cincotto, F.H.; Machado, S.A.S. A synergistic combination of reduced graphene oxide and antimony nanoparticles for estriol hormone detection. Sens. Actuators B Chem. 2015, 210, 453-459. [CrossRef]

19. Shao, Y.; Wang, J.; Wu, H.; Liu, J.; Aksay, I.A.; Lin, Y. Graphene Based Electrochemical Sensors and Biosensors: A Review. Electroanalysis 2010, 22, 1027-1036. [CrossRef]

20. Chen, D.; Feng, H.; Li, J. Graphene Oxide: Preparation, Functionalization, and Electrochemical Applications. Chem. Rev. 2012, 112, 6027-6053. [CrossRef]

21. Saha, K.; Agasti, S.S.; Kim, C.; Li, X.; Rotello, V.M. Gold Nanoparticles in Chemical and Biological Sensing. Chem. Rev. 2012, 112, 2739-2779. [CrossRef]

22. Zayats, M.; Baron, R.; Popov, I.; Willner, I. Biocatalytic growth of Au nanoparticles: From mechanistic aspects to biosensors design. Nano Lett. 2005, 5, 21-25. [CrossRef] [PubMed]

23. Guo, S.; Huang, Y.; Jiang, Q.; Sun, Y.; Deng, L.; Liang, Z.; Du, Q.; Xing, J.; Zhao, Y.; Wang, P.C.; et al. Enhanced Gene Delivery and siRNA Silencing by Gold Nanoparticles Coated with Charge-Reversal Polyelectrolyte. ACS Nano 2010, 4, 5505-5511. [CrossRef] [PubMed]

24. Rosi, N.L.; Giljohann, D.A.; Thaxton, C.S.; Lytton-Jean, A.K.R.; Han, M.S.; Mirkin, C.A. Oligonucleotide-Modified Gold Nanoparticles for Intracellular Gene Regulation. Science 2006, 312, 1027-1030. [CrossRef] [PubMed]

25. Pokharkar, V.; Bhumkar, D.; Suresh, K.; Shinde, Y.; Gairola, S.; Jadhav, S.S. Gold nanoparticles as a potential carrier for transmucosal vaccine delivery. J. Biomed. Nanotechnol. 2011, 7, 57-59. [CrossRef] [PubMed]

26. Zhou, X.; Zhang, X.; Yu, X.; Zha, X.; Fu, Q.; Liu, B.; Wang, X.; Chen, Y.; Chen, Y.; Shan, Y.; et al. The effect of conjugation to gold nanoparticles on the ability of low molecular weight chitosan to transfer DNA vaccine. Biomaterials 2008, 29, 111-117. [CrossRef]

27. Hall, W.P.; Ngatia, S.N.; Van Duyne, R.P. LSPR Biosensor Signal Enhancement Using Nanoparticle-Antibody Conjugates. J. Phys. Chem. C 2011, 115, 1410-1414. [CrossRef]

28. Pissuwan, D.; Cortie, C.H.; Valenzuela, S.M.; Cortie, M.B. Functionalised gold nanoparticles for controlling pathogenic bacteria. Trends Biotechnol. 2010, 28, 207-213. [CrossRef] [PubMed]

29. Pivodová, V.; Franková, J.; Galandáková, A.; Ulrichová, J. In Vitro AuNPs' Cytotoxicity and Their Effect on Wound Healing. Nanobiomedicine 2015, 2, 2-7. [CrossRef]

30. Meir, R.; Shamalov, K.; Betzer, O.; Motiei, M.; Horovitz-Fried, M.; Yehuda, R.; Popovtzer, A.; Popovtzer, R.; Cohen, C.J. Nanomedicine for Cancer Immunotherapy: Tracking Cancer-Specific T-Cells in Vivo with Gold Nanoparticles and CT Imaging. ACS Nano 2015, 9, 6363-6372. [CrossRef]

31. Wang, F.; Wang, Y.-C.; Dou, S.; Xiong, M.-H.; Sun, T.-M.; Wang, J. Doxorubicin-Tethered Responsive Gold Nanoparticles Facilitate Intracellular Drug Delivery for Overcoming Multidrug Resistance in Cancer Cells. ACS Nano 2011, 5, 3679-3692. [CrossRef] 
32. Megiel, E. Surface modification using TEMPO and its derivatives. Adv. Colloid Interface Sci. 2017, 250, 158-184. [CrossRef] [PubMed]

33. Hummers, W.S.; Offeman, R.E. Preparation of Graphitic Oxide. J. Am. Chem. Soc. 1958, 80, 1339. [CrossRef]

34. Souza, J.S.; Hirata, F.T.H.; Corio, P. Microwave-assisted synthesis of bismuth vanadate nanoflowers decorated with gold nanoparticles with enhanced photocatalytic activity. J. Nanopart. Res. 2019, 21, 35. [CrossRef]

35. Schmidt, R.; Prado-Gonjal, J.; Morán, E. Microwave-Assisted Hydrothermal Synthesis of Nanoparticles. In CRC Concise Encyclopedia of Nanotechnology; Kharisov, B.I., Ortiz-Mendez, O.V.K.U., Eds.; CRC Press Taylor \& Francis Group: Boca Raton, FL, USA, 2018; pp. 585-596. ISBN 9781466580343.

36. Ali, G.A.M.; Megiel, E.; Romański, J.; Algarni, H.; Chong, K.F. A wide potential window symmetric supercapacitor by TEMPO functionalized MWCNTs. J. Mol. Liq. 2018, 271, 31-39. [CrossRef]

37. He, D.; Shen, L.; Zhang, X.; Wang, Y.; Bao, N.; Kung, H.H. An efficient and eco-friendly solution-chemical route for preparation of ultrastable reduced graphene oxide suspensions. AIChE J. 2014, 60, 2757-2764. [CrossRef]

(C) 2019 by the authors. Licensee MDPI, Basel, Switzerland. This article is an open access article distributed under the terms and conditions of the Creative Commons Attribution (CC BY) license (http://creativecommons.org/licenses/by/4.0/). 